\title{
Serum cystatin C predicts vancomycin trough levels better than serum creatinine in hospitalized patients: a cohort study
}

\author{
Erin N Frazee ${ }^{1 *}$, Andrew D Rule ${ }^{2,3}$, Sandra M Herrmann ${ }^{2}$, Kianoush B Kashani ${ }^{2,4}$, Nelson Leung ${ }^{2}$, Abinash Virk \\ Nikolay Voskoboev ${ }^{6}$ and John C Lieske 2,6
}

\begin{abstract}
Introduction: Serum cystatin C can improve glomerular filtration rate (GFR) estimation over creatinine alone, but whether this translates into clinically relevant improvements in drug dosing is unclear.

Methods: This prospective cohort study enrolled adults receiving scheduled intravenous vancomycin while hospitalized at the Mayo Clinic in 2012. Vancomycin dosing was based on weight, serum creatinine with the Cockcroft-Gault equation, and clinical judgment. Cystatin C was later assayed from the stored serum used for the creatinine-based dosing. Vancomycin trough prediction models were developed by using factors available at therapy initiation. Residuals from each model were used to predict the proportion of patients who would have achieved the target trough with the model compared with that observed with usual care.
\end{abstract}

Results: Of 173 patients enrolled, only 35 (20\%) had a trough vancomycin level within their target range (10 to $15 \mathrm{mg} / \mathrm{L}$ or 15 to $20 \mathrm{mg} / \mathrm{L})$. Cystatin C-inclusive models better predicted vancomycin troughs than models based upon serum creatinine alone, although both were an improvement over usual care. The optimal model used estimated GFR by the Chronic Kidney Disease Epidemiology Collaborative (CKD-EPI) creatinine-cystatin c equation $\left(R^{2}=0.580\right)$. This model is expected to yield $54 \%$ (95\% confidence interval $45 \%$ to $\left.61 \%\right)$ target trough attainment ( $P<0.001$ compared with the $20 \%$ with usual care).

Conclusions: Vancomycin dosing based on standard care with Cockcroft-Gault creatinine clearance yielded poor trough achievement. The developed dosing model with estimated GFR from CKD-EPI creatinine-cystatin c could yield a 2.5 -fold increase in target trough achievement compared with current clinical practice. Although this study is promising, prospective validation of this or similar cystatin C-inclusive dosing models is warranted.

\section{Introduction}

The use of vancomycin, an anti-infective active against Gram-positive organisms, has increased nearly 100 -fold over the last three decades [1-3]. This surge in utilization likely reflects the growing prevalence of staphylococcal infections, often methicillin-resistant Staphylococcus aureus (MRSA), for which vancomycin is considered first-line therapy $[4,5]$. Since vancomycin has a narrow therapeutic window, routine therapeutic drug monitoring with serum trough concentrations is recommended [4,5]. Unfortunately,

\footnotetext{
* Correspondence: frazee.erin@mayo.edu

${ }^{1}$ Hospital Pharmacy Services, Mayo Clinic, 200 First Street SW, Rochester, MN 55905, USA

Full list of author information is available at the end of the article
}

recent evidence suggests that vancomycin dosing in clinical practice fails to reach trough targets in more than $50 \%$ of patients [6].

Although the precise reason for failure to achieve vancomycin targets is unknown, it may pertain to suboptimal assessment of glomerular filtration rate (GFR) because nearly $90 \%$ of the drug is eliminated renally $[5,7,8]$. The GFR in vancomycin dosing algorithms is most commonly estimated by Cockcroft-Gault creatinine clearance [8-10]. Unfortunately, these dosing algorithms were developed before serum creatinine assays were standardized. Also, creatinine-based GFR estimates are influenced by non-GFR factors not adequately accounted for by adjustments for age, sex, ethnicity, and weight. Finally, rapid 
changes in GFR among acutely ill patients are poorly captured by serum creatinine monitoring [11-19].

Cystatin $\mathrm{C}$ is another endogenous biomarker that, in combination with serum creatinine, improves GFR estimation relative to creatinine alone [12,20-24]. Unfortunately, the literature on cystatin C-guided medication dosing remains limited [25-31]. Pharmacokinetic analyses suggest that cystatin $\mathrm{C}$ may better predict vancomycin clearance than creatinine, yet the relationship of this biomarker with steady-state trough levels remains unclear [26-28]. Furthermore, it is unknown whether the combination of creatinine and cystatin $\mathrm{C}$ can be used to predict vancomycin troughs better than either GFR marker used in isolation. The purpose of this study was to determine the optimal model to predict vancomycin trough levels using serum creatinine or cystatin $\mathrm{C}$ or both. Results suggest that vancomycin dosing algorithms that employ cystatin $\mathrm{C}$ should be developed for prospective validation.

\section{Materials and methods Setting and participants}

This prospective cohort study enrolled hospitalized adults at the Mayo Clinic in Rochester, Minnesota, who received intravenous vancomycin between March and October 2012 and had Minnesota research authorization [32]. The Mayo Clinic Institutional Review Board approved the protocol and waived the need for informed consent because the study was considered minimal risk. Other eligibility criteria included the measurement of creatinine upon vancomycin initiation (enrollment creatinine), availability of stored serum from this same sample for cystatin $\mathrm{C}$ measurement, and a steady-state vancomycin level. Patients were excluded if they developed stage 2 or stage 3 acute kidney injury (AKI) at baseline or prior to the vancomycin level, because changing renal function would prohibit the achievement of a steady state during vancomycin dosing [33]. In such cases, clinicians routinely administer a single dose of vancomycin and perform serial serum concentration monitoring to determine the appropriate time for a re-dose. Patients who received vancomycin at an inconsistent dose or interval were also excluded as were individuals with a body mass index of greater than $32 \mathrm{~kg} / \mathrm{m}^{2}$ due to altered vancomycin pharmacokinetics in obesity [34].

Institutionally endorsed vancomycin dosing and monitoring recommendations were in place throughout the study $[5,10,11]$. Briefly, a vancomycin loading dose of 20 to $30 \mathrm{mg} / \mathrm{kg}$ and a maintenance dose of 15 to $20 \mathrm{mg} / \mathrm{kg}$ based on actual body weight were recommended for all patients. Dosing intervals were informed primarily by the Cockcroft-Gault creatinine clearance $[10,11,35]$. Regimens were tailored by the care team according to severity of infection and other determinants of renal function (that is, urine output), if available. Ultimately, the primary service, supported by a clinical pharmacist, both without cystatin $\mathrm{C}$ levels, established an individualized vancomycin regimen for each patient. In accordance with national guidelines, each regimen was designed to achieve a target vancomycin trough level, either between 10 and $15 \mathrm{mg} / \mathrm{L}$ or between 15 and $20 \mathrm{mg} / \mathrm{L}$, appropriate for the suspected or documented source(s) of infection [4,5]. Specifically, individuals with bacteremia, endocarditis, osteomyelitis, meningitis, or pneumonia with a suspected association with $S$. aureus were assigned a goal trough range of 15 to $20 \mathrm{mg} / \mathrm{L}$. In all other cases, the target trough range assigned was 10 to $15 \mathrm{mg} / \mathrm{L}$. Vancomycin dosing interval reflects GFR and the anticipated drug half-life. Using guideline recommendations, trough levels were all drawn immediately before the fourth dose of vancomycin to approximate steady-state conditions ( 4 to 5 half-lives) $[4,5]$.

\section{Measures}

Patient demographics (age, gender, race, and ethnicity), comorbid conditions, severity of illness, and admission diagnosis were each noted. Other abstracted data included source of infection, vancomycin dose and inter$\mathrm{val}$, and routine laboratory data. Vancomycin level was analyzed by using the Syva Emit 2000 Vancomycin Assay (Siemens Healthcare Diagnostics, Inc., Newark, DE, USA). For the 12 (7\%) individuals with undetectable vancomycin levels $(<5.0 \mathrm{mg} / \mathrm{L})$, serum levels were recorded as $2.5 \mathrm{mg} / \mathrm{L}$. Creatinine measurement was performed by using the standardized-isotope dilution mass spectrometry (IDMS) traceable-Roche enzymatic creatinine assay (Roche, Basel, Switzerland). In patients receiving intravenous catecholamines, known to interfere with enzymatic assays, an IDMS traceable Roche rateJaffe creatinine assay was used instead (Roche Cobas Integra 400 Plus chemistry analyzer). Cystatin $C$ was measured on stored serum used for the enrollment creatinine with a particle-enhanced turbidimetric assay (Gentian AS, Moss, Norway). This assay is traceable to the same international certified cystatin $\mathrm{C}$ reference material (ERM-DA471/IFCC) used to develop the cystatin C-based Chronic Kidney Disease Epidemiology Collaborative (CKD-EPI) equations [12,36].

\section{Data analysis}

Continuous data were summarized by using mean \pm standard deviation (SD) or median with interquartile range depending on distribution. The Wilcoxon signedrank test was used to detect intra-individual differences in GFR estimates. Frequencies (percentages) were used to describe discrete data. The Pearson's chi-square test or Fisher's exact test analyzed independent binary outcomes between groups, whereas the McNemar's test was 
used for paired data, including trough achievement between dosing approaches.

Linear regression was used to develop predictive models for the vancomycin trough level (Figure 1). To develop models that would be clinically useful, predictors were included in the model only if readily available at baseline. Multivariate models included various combinations of age, sex, race, height (centimeters), weight (kilograms), body mass index (kilograms per square meter), baseline creatinine (milligrams per deciliter), and baseline cystatin C (milligrams per liter). Logarithmic transformation of serum creatinine and cystatin $\mathrm{C}$ improved model fit. The change in creatinine from pre-enrollment to enrollment (usually a 24-hour interval), total vancomycin dose received prior to trough (sum of the first three doses), use of a loading dose, dosing interval, and estimated GFR (eGFR) were also assessed. eGFR was determined by the Cockcroft-Gault equation and the three CKD-EPI equations (creatinine, cystatin $\mathrm{C}$, or creatinine and cystatin $\mathrm{C}$ ) re-expressed in milliliters per minute by multiplying by body surface area (BSA) derived from the Du Bois formula divided by $1.73 \mathrm{~m}^{2}[12,37]$.

The target range for the vancomycin trough (10 to $15 \mathrm{mg} / \mathrm{L}$ or 15 to $20 \mathrm{mg} / \mathrm{L}$ ) was based on the clinical indication for treatment. We analyzed our regression models to determine how well they would be expected to achieve vancomycin troughs within target ranges compared with usual clinical practice. First, model residuals for each patient were calculated on the basis of the differences between predicted and observed vancomycin trough levels. Model residuals represent all the unpredictable variation in vancomycin trough levels. Then model residuals were added to the target trough level (either 12.5 if target trough range was 10 to $15 \mathrm{mg} / \mathrm{L}$ or 17.5 if target trough range was 15 to $20 \mathrm{mg} / \mathrm{L}$ ) to determine the expected trough. Thus, the expected trough is based on both the predictable variation ( 12.5 or $17.5 \mathrm{mg} / \mathrm{L})$ and the unpredictable variation (residual) from the regression model. The proportion of individuals with an expected trough within their target trough range was then calculated.

To address potential over-fitting of models for trough level prediction, cross-validation was performed on the model with the best fit (highest $R^{2}$ ). The final model was re-derived by using $90 \%$ of the sample $(\mathrm{n}=156)$ and validated in the remaining $10 \%(\mathrm{n}=17)$. This cross-validation was repeated 10 times to determine the mean proportion of expected levels within the target trough range across the 10 replications. All analyses were performed with JMP version 9 statistical software (SAS Institute Inc., Cary, NC, USA).

\section{Results}

Of the 552 patients screened for eligibility, 173 individuals were enrolled in the study. The majority of excluded patients lacked an adequate stored specimen for cystatin C measurement ( $n=189)$, were obese $(n=99)$, or declined research authorization for the study $(\mathrm{n}=53)$ (Figure 2). No patients were excluded for KDIGO (Kidney Disease: Improving Global Outcomes) stage 2 or stage 3 AKI. The final cohort was $59 \pm 16$ (mean $\pm \mathrm{SD}$ ) years old, $54 \%$ male, and predominately Caucasian (95\%). The mean BSA of included patients was $1.86 \pm 0.2 \mathrm{~m}^{2}$ with a range of 1.29 to $2.52 \mathrm{~m}^{2}$. Moderate to severe chronic kidney disease with a

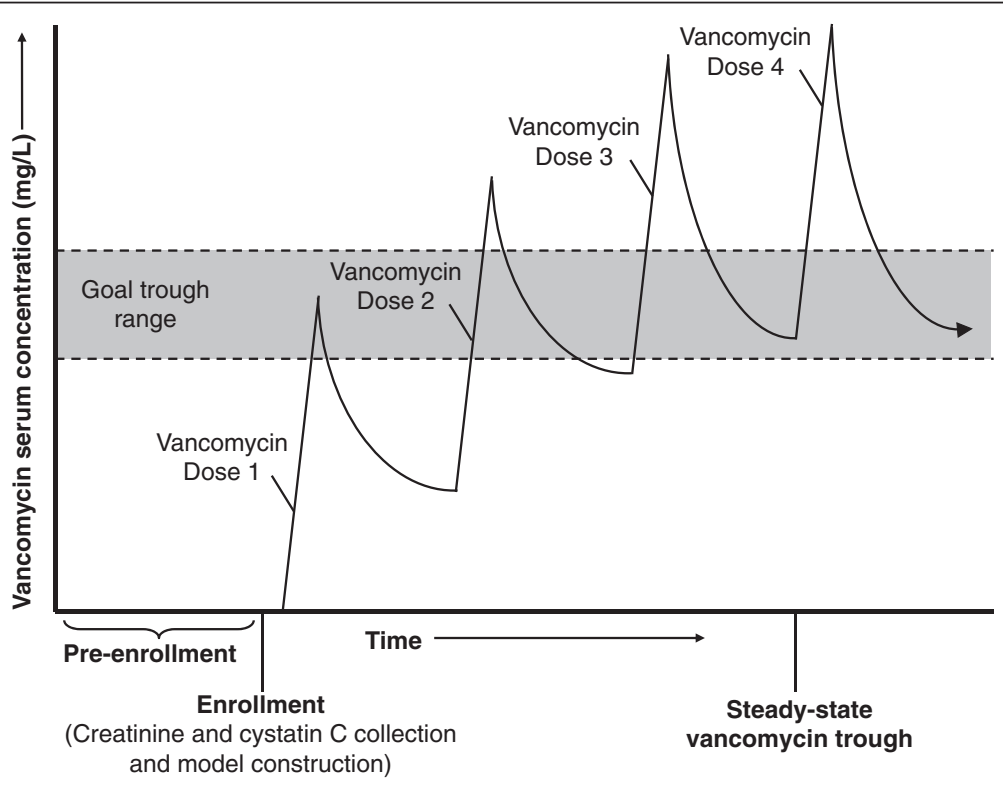

Figure 1 Patient enrollment flowchart. 


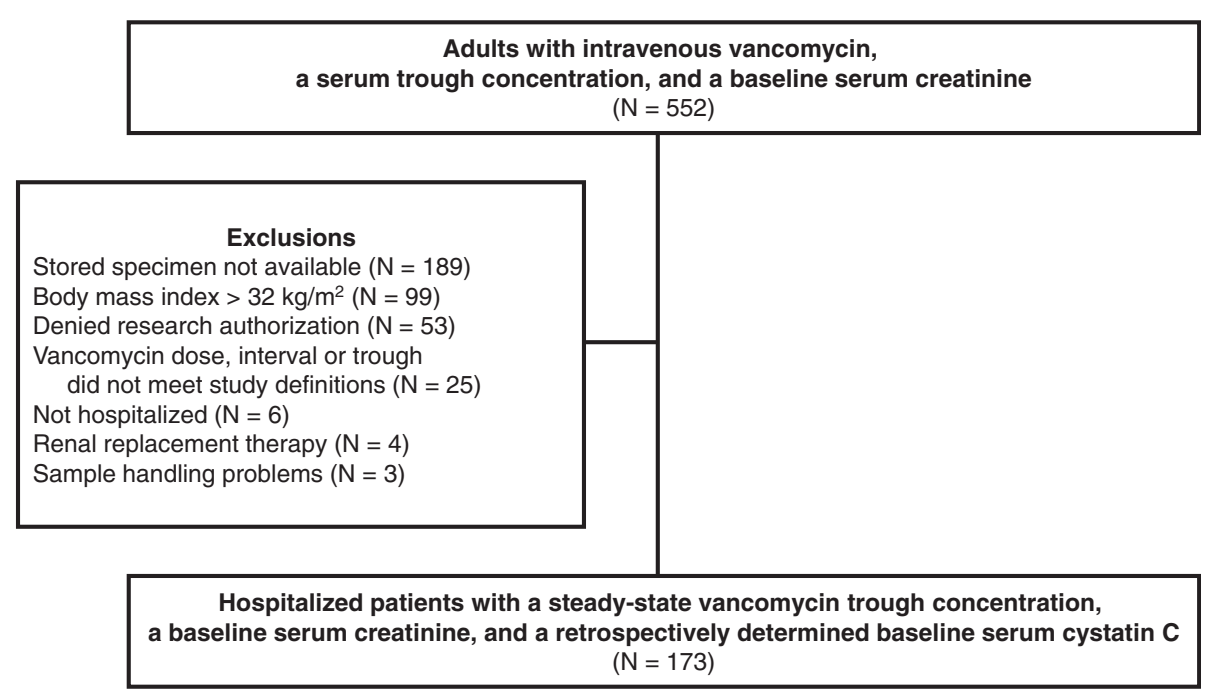

Figure 2 Overview of the study protocol. Factors available at baseline, prior to the first vancomycin dose, were used to develop vancomycin trough level prediction models. Steady-state vancomycin trough adequacy, prior to the fourth dose, was determined according to individualized target ranges based on suspected or documented source(s) of infection.

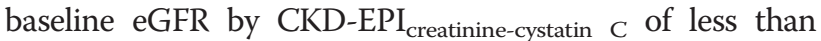
$60 \mathrm{~mL} / \mathrm{min}$ was evident in $20 \%$ of patients (Table 1 ). The

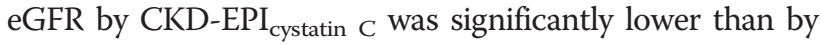
CKD-EPI creatinine $(-14 \pm 25 \mathrm{~mL} / \mathrm{min}, P<0.001)$. A creatinine value prior to the study baseline (Figure 1) was available in 122 (71\%) individuals. Using this value, stage 1 AKI (an at least $0.3 \mathrm{mg} / \mathrm{dL}$ creatinine increase from baseline), though not an explicit exclusion criterion, affected only four (3\%) patients in the included sample. The administered vancomycin maintenance dose compared well with institutional and national guidelines $(16.3 \pm 2.4 \mathrm{mg} / \mathrm{kg})$. Dosing frequency differed from the institutional recommendations in 132 (76\%) patients, most commonly because providers selected less frequent dosing intervals. The target troughs were 10 to $15 \mathrm{mg} / \mathrm{L}$ for $40 \%$ of patients and 15 to $20 \mathrm{mg} / \mathrm{L}$ for $60 \%$ of patients.

Univariate analyses demonstrated a significant association between steady-state vancomycin trough level and each of the following variables: $\log$ creatinine, log cystatin C, eGFR, and total pre-trough vancomycin dose (Table 2). All multivariable models included vancomycin total dose and dosing interval. Separate models were developed by using the serum kidney function markers (serum creatinine or cystatin $\mathrm{C}$ or both) alone and as part of each of the four kidney function equations. Height was removed from the serum kidney function marker models as it was not a statistically significant predictor. Owing to the low prevalence of non-Caucasian race $(5 \%)$, this predictor was also omitted. Models included age, sex, and weight, when not imbedded in GFR calculations. The models with the best fit and target trough achievement included cystatin $\mathrm{C}$ (Table 3 and Figure 3). The published CKD-EPI equations report
eGFR in milliliters per minute per $1.73 \mathrm{~m}^{2}$ [12]. Either converting CKD-EPI eGFR to milliliters per minute or adding weight improved model fit, but doing both did not further improve fit (Additional file 1).

The vancomycin trough achieved target in only 35 patients (20\%) during routine clinical care with maintenance doses of 15 to $20 \mathrm{mg} / \mathrm{kg}$ and intervals informed by the CockcroftGault creatinine clearance. Trough achievement in clinical practice was $22 \%$ when institutional dosing interval recommendations were followed compared with $20 \%$ when not followed $(P=0.8)$. Application of the model with the greatest power (model 7: eGFR with CKD-EPI creatinine-cystatin C; $^{2}=$ 0.580 ) is expected to yield about a 2.5 -fold greater trough achievement than that which resulted from routine clinical practice ( $54 \%$ versus $20 \%$; $P<0.0001$ versus observed trough). Among patients with CKD (defined as CKD$E P I_{\text {creatinine-cystatin } C}$ of less than $60 \mathrm{~mL} / \mathrm{min}$ ), the improvement between observed and expected trough achievement was modest ( $34 \%$ versus $43 \%, P=0.4$ ). In contrast, among patients without CKD (defined as CKD-EPI ${ }_{\text {creatinine-cystatin C }}$ of more than $60 \mathrm{~mL} / \mathrm{min}$ ), the improvement between observed and expected trough achievement was much greater $(17 \%$ versus $57 \%, P<0.001)$. Notably, low trough levels were associated with a high GFR (Figure 4; $P<0.0001$ ). Cross-validation of model 7 to address potential overfitting of the data projected a slightly lower target trough achievement of $51 \%$ across the 10 replications instead of $54 \%$.

\section{Discussion}

In this study, only $20 \%$ of patients achieved a serum vancomycin trough level within their target range under usual care based on a combination of the Cockcroft- 
Table 1 Baseline patient characteristics, demographics, and infection characteristics

\begin{tabular}{|c|c|}
\hline Characteristic & Patients $(n=173)$ \\
\hline Age, years & $59 \pm 16$ \\
\hline Male, n (\%) & $93(54)$ \\
\hline Caucasian, n (\%) & $164(95)$ \\
\hline Body mass index, $\mathrm{kg} / \mathrm{m}^{2}$ & $25.5 \pm 3.6$ \\
\hline Body surface area, $\mathrm{m}^{2}$ & $1.9 \pm 0.2$ \\
\hline Non-operative admission diagnosis, n (\%) & $110(65)$ \\
\hline Intensive care unit, n (\%) & $37(22)$ \\
\hline \multicolumn{2}{|l|}{ Renal parameters } \\
\hline $\begin{array}{l}\text { History of moderate to severe kidney } \\
\text { disease, } \mathrm{n}(\%)\end{array}$ & $22(13)$ \\
\hline Serum creatinine, $\mathrm{mg} / \mathrm{dL}^{\mathrm{b}}$ & $0.8 \pm 0.4$ \\
\hline Cystatin C, mg/L & $1.1 \pm 0.5$ \\
\hline \multicolumn{2}{|l|}{$\mathrm{eGFR}, \mathrm{mL} / \mathrm{min}^{\mathrm{c}}$} \\
\hline Cockcroft-Gault & $108 \pm 48$ \\
\hline CKD-EPI $\left.\right|_{\text {creatinine }}$ & $98 \pm 29$ \\
\hline CKD-EPI $\left.\right|_{\text {cystatin C }}$ & $84 \pm 37$ \\
\hline CKD-EPI $I_{\text {creatinine-cystatin C }}$ & $91 \pm 33$ \\
\hline \multicolumn{2}{|l|}{ Infectious source, $n(\%)^{d}$} \\
\hline Pulmonary & $50(29)$ \\
\hline Bacteremia & $36(21)$ \\
\hline Intra-abdominal & $28(16)$ \\
\hline Skin and soft tissue infection & $28(16)$ \\
\hline Musculoskeletal & $27(16)$ \\
\hline Other/unknown ${ }^{\mathrm{e}}$ & $43(25)$ \\
\hline \multicolumn{2}{|l|}{ Microbiology } \\
\hline Culture positive, n (\%) & $98(57)$ \\
\hline Monomicrobial & 51 \\
\hline \multicolumn{2}{|l|}{ Specific Gram-positive organisms isolated } \\
\hline Coagulase-negative Staphylococcus spp. & 25 \\
\hline Methicillin-susceptible Staphylococcus aureus & 15 \\
\hline Methicillin-resistant S. aureus & 10 \\
\hline Enterococcus spp. & 22 \\
\hline \multicolumn{2}{|l|}{ Vancomycin } \\
\hline Loading dose used, n (\%) & $64(37)$ \\
\hline \multicolumn{2}{|l|}{ Maintenance dose } \\
\hline Non-weight based, mg & $1,206 \pm 263$ \\
\hline Weight-based, mg/kg & $16.3 \pm 2.4$ \\
\hline Dose between 14 and 21 mg/kg, n (\%) & $152(88)$ \\
\hline \multicolumn{2}{|l|}{ Interval, n (\%) } \\
\hline 8 hours & $8(5)$ \\
\hline 12 hours & $148(86)$ \\
\hline 24 hours & $17(10)$ \\
\hline
\end{tabular}

Table 1 Baseline patient characteristics, demographics, and infection characteristics (Continued)

\author{
Goal trough according to site of infection
$10-15 \mathrm{mg} / \mathrm{L}, \mathrm{n}(\%)$
$69(40)$
$15-20 \mathrm{mg} / \mathrm{L}, \mathrm{n}(\%)$
$104(60)$ \\ Trough level, mg/L \\ $12.5 \pm 6.0$ \\ ${ }^{\mathrm{a} V}$ Values expressed as mean \pm standard deviation unless noted. ${ }^{\mathrm{b}} \mathrm{To}$ convert the \\ values for serum creatinine to micromoles per liter, multiply by 88.4 . ${ }^{\mathrm{C}} \mathrm{To}$ \\ convert from $\mathrm{mL} / \mathrm{min}$ per $1.73^{2}$ multiply by $\left[\left(0.007184^{*}\right.\right.$ height $(\mathrm{cm})^{0.725 *}$ weight \\ $\left.(\mathrm{kg})^{0.425}\right) / 1.73$ ] [37]. ${ }^{\mathrm{d}}$ Sum of percentages exceeds 100 due to multiple sources \\ of suspected/documented infection. ${ }^{e}$ Other sources include genitourinary, \\ febrile neutropenia, cardiovascular, central nervous system, acute otitis media, \\ and prophylaxis. CKD-EPI, Chronic Kidney Disease Epidemiology Collaborative; \\ eGFR, estimated glomerular filtration rate; n, number.
}

Gault equation, manufacturer guidelines, and clinician judgment. To determine whether clinically available data could be used to predict trough levels, we developed novel models based on serum creatinine, cystatin $C$, or eGFR with the Cockcroft-Gault and CKD-EPI equations. The optimal model used the CKD-EPI creatinine-cystatin $C$ equation for eGFR and is projected to improve trough achievement to greater than $50 \%$. When these models were used, a practical set of dosing recommendations for vancomycin using the CKD-EPI equations could be developed for prospective testing.

Table 2 Univariate predictors of vancomycin trough level, $\mathrm{mg} / \mathrm{L}$

\begin{tabular}{|c|c|c|}
\hline Potential baseline predictor & Beta & $P$ value \\
\hline \multicolumn{3}{|c|}{ Demographic and anthropometric data } \\
\hline Age, year & 0.057 & 0.06 \\
\hline Male & -0.076 & 0.97 \\
\hline Height, $\mathrm{cm}$ & -0.015 & 0.72 \\
\hline Weight, kg & 0.039 & 0.12 \\
\hline \multicolumn{3}{|l|}{ Kidney function markers } \\
\hline Log creatinine, mg/dL & 5.320 & $<0.001$ \\
\hline Log cystatin C, mg/L & 9.592 & $<0.001$ \\
\hline \multicolumn{3}{|c|}{ Equations for estimated GFR, $\mathrm{mL} / \mathrm{min}^{\mathrm{a}}$} \\
\hline Cockcroft-Gault & -0.041 & $<0.001$ \\
\hline CKD-EPI $\left.\right|_{\text {creatinine }}$ & -0.076 & $<0.001$ \\
\hline CKD-EPI cystatin C $_{\text {c }}$ & -0.094 & $<0.001$ \\
\hline CKD-EPI $\left.\right|_{\text {creatinine-cystatin C }}$ & -0.101 & $<0.001$ \\
\hline \multicolumn{3}{|l|}{ Vancomycin parameters } \\
\hline Loading dose given & 1.412 & 0.15 \\
\hline Total pre-trough dose, $\mathrm{g}$ & 1.635 & 0.004 \\
\hline \multicolumn{3}{|l|}{ Interval } \\
\hline Every 8 hours & 2.216 & 0.33 \\
\hline Every 12 hours & REF & - \\
\hline Every 24 hours & -0.943 & 0.56 \\
\hline
\end{tabular}

To convert from $\mathrm{mL} / \mathrm{min}$ per $1.73^{2}$ multiply by $\left[\left(0.007184^{*}\right.\right.$ height $(\mathrm{cm})^{0.725 *}$ weight $\left.(\mathrm{kg})^{0.425}\right) / 1.73$ ] [37]. CKD-EPI, Chronic Kidney Disease Epidemiology Collaborative; GFR, glomerular filtration rate; REF, reference. 
Table 3 Predictive models for vancomycin trough level, $\mathrm{mg} / \mathrm{L}$

\begin{tabular}{|c|c|c|c|c|}
\hline Model variable $^{a}$ & Beta & $P$ value & $\begin{array}{l}\text { Model } \\
\text { fit }\left(R^{2}\right)\end{array}$ & $\begin{array}{c}\text { Target trough } \\
\text { achievement } \\
(95 \% \mathrm{Cl}) \\
\end{array}$ \\
\hline $\begin{array}{l}\text { Model 1: log } \\
\text { creatinine }\end{array}$ & & & 0.306 & $\begin{array}{c}35 \% \\
(28 \%-42 \%)\end{array}$ \\
\hline Intercept & 9.10 & 0.002 & & \\
\hline Age, years & 0.0886 & 0.002 & & \\
\hline Male & -2.30 & 0.02 & & \\
\hline Weight, kg & -0.0136 & 0.004 & & \\
\hline Vancomycin total dose, $g$ & 3.28 & $<0.001$ & & \\
\hline Every 8-hour interval & 3.18 & 0.1 & & \\
\hline Every 12-hour interval & REF & - & & \\
\hline Every 24-hour interval & -6.61 & $<0.001$ & & \\
\hline Log baseline creatinine & 8.80 & $<0.001$ & & \\
\hline $\begin{array}{l}\text { Model 2: log } \\
\text { cystatin C }\end{array}$ & & & 0.559 & $\begin{array}{c}52 \% \\
(45 \%-59 \%)\end{array}$ \\
\hline Intercept & 10.2 & $<0.001$ & & \\
\hline Age, years & -0.00578 & 0.8 & & \\
\hline Male & -2.32 & 0.004 & & \\
\hline Weight, kg & -0.0708 & 0.05 & & \\
\hline Vancomycin total dose, $g$ & 2.50 & $<0.001$ & & \\
\hline Every 8-hour interval & 4.25 & 0.009 & & \\
\hline Every 12-hour interval & REF & - & & \\
\hline Every 24-hour interval & -6.66 & $<0.001$ & & \\
\hline Log baseline cystatin C & 12.6 & $<0.001$ & & \\
\hline $\begin{array}{l}\text { Model 3: log } \\
\text { creatinine and } \\
\text { log cystatin C }\end{array}$ & & & 0.575 & $\begin{array}{c}53 \% \\
(45 \%-60 \%)\end{array}$ \\
\hline Intercept & 11.5 & $<0.001$ & & \\
\hline Age, years & 0.00582 & 0.8 & & \\
\hline Male & -2.64 & 0.001 & & \\
\hline Weight, kg & -0.0931 & 0.01 & & \\
\hline Vancomycin total dose, g & 2.70 & $<0.001$ & & \\
\hline Every 8-hour interval & 4.15 & 0.009 & & \\
\hline Every 12-hour interval & REF & - & & \\
\hline Every 24-hour interval & -7.90 & $<0.001$ & & \\
\hline Log baseline creatinine & 2.89 & 0.01 & & \\
\hline Log baseline cystatin C & 11.3 & $<0.001$ & & \\
\hline $\begin{array}{l}\text { Model 4: eGFR with } \\
\text { Cockcroft-Gault }\end{array}$ & & & 0.269 & $\begin{array}{c}33 \% \\
(26 \%-40 \%)\end{array}$ \\
\hline Intercept & 10.3 & $<0.001$ & & \\
\hline Vancomycin total dose, $\mathrm{g}$ & 2.66 & $<0.001$ & & \\
\hline Every 8-hour interval & 3.20 & 0.1 & & \\
\hline Every 12-hour interval & REF & - & & \\
\hline Every 24-hour interval & -4.11 & 0.008 & & \\
\hline eGFR with Cockcroft- & -0.0704 & $<0.001$ & & \\
\hline
\end{tabular}

Table 3 Predictive models for vancomycin trough level, mg/L (Continued)

\begin{tabular}{|c|c|c|c|c|}
\hline $\begin{array}{l}\text { Model 5: eGFR with } \\
\text { CKD-EPI } \\
\text { creatinine }\end{array}$ & & & 0.394 & $\begin{array}{c}38 \% \\
(31 \%-46 \%)\end{array}$ \\
\hline Intercept & 16.4 & $<0.001$ & & \\
\hline Vancomycin total dose, $\mathrm{g}$ & 3.35 & $<0.001$ & & \\
\hline Every 8-hour interval & 3.47 & 0.06 & & \\
\hline Every 12-hour interval & REF & - & & \\
\hline Every 24-hour interval & -7.58 & $<0.001$ & & \\
\hline $\begin{array}{l}\text { eGFR with CKD-EPI } \\
\mathrm{mL} / \mathrm{min}^{\mathrm{b}}\end{array}$ & -0.163 & $<0.001$ & & \\
\hline $\begin{array}{l}\text { Model 6: eGFR with } \\
\text { CKD-EPI }\end{array}$ & & & 0.538 & $\begin{array}{c}51 \% \\
(44 \%-59 \%)\end{array}$ \\
\hline Intercept & 14.3 & $<0.001$ & & \\
\hline Vancomycin total dose, $\mathrm{g}$ & 2.61 & $<0.001$ & & \\
\hline Every 8-hour interval & 4.91 & $<0.001$ & & \\
\hline Every 12-hour interval & REF & - & & \\
\hline Every 24-hour interval & -5.94 & $<0.001$ & & \\
\hline $\begin{array}{l}\text { eGFR with CKD-EPI } \\
\mathrm{mL} / \mathrm{min}^{\mathrm{b}}\end{array}$ & -0.134 & $<0.001$ & & \\
\hline $\begin{array}{l}\text { Model 7: eGFR with } \\
\text { CKD-EPI creatinine-cystatin C }\end{array}$ & & & 0.580 & $\begin{array}{c}54 \% \\
(45 \%-61 \%)\end{array}$ \\
\hline Intercept & 16.7 & $<0.001$ & & \\
\hline Vancomycin total dose, $\mathrm{g}$ & 2.95 & $<0.001$ & & \\
\hline Every 8-hour interval & 4.84 & 0.002 & & \\
\hline Every 12-hour interval & REF & - & & \\
\hline Every 24-hour interval & -7.70 & $<0.001$ & & \\
\hline $\begin{array}{l}\text { eGFR with } \\
\text { CKD-EPI } I_{\text {creatinine-cystatin C }} \\
\mathrm{mL} / \mathrm{min}^{\mathrm{b}}\end{array}$ & -0.163 & $<0.001$ & & \\
\hline
\end{tabular}

${ }^{\mathrm{a} V a n c o m y c i n ~ t o t a l ~ d o s e ~ r e p r e s e n t s ~ t h e ~ c u m u l a t i v e ~ g r a m s ~ o f ~ v a n c o m y c i n ~ g i v e n ~}$ prior to trough level being drawn. Per the study definition, this represents three doses of vancomycin therapy. ${ }^{\text {T}}$ To convert from milliliters per minute per $1.73^{2}$, multiply by [(0.007184*height $(\mathrm{cm})^{0.725 *}$ weight $\left.\left.(\mathrm{kg})^{0.425}\right) / 1.73\right]$ [37]. Cl, confidence interval; CKD-EPI, Chronic Kidney Disease Epidemiology Collaborative; eGFR estimated glomerular filtration rate; REF, reference.

Cystatin $\mathrm{C}$, an endogenous proteinase inhibitor, is one of the first surrogates of GFR to emerge as a viable and practical alternative to creatinine in the last several decades $[33,38]$. Minimal data regarding the use of cystatin $\mathrm{C}$-based medication dosing have been published. The present study demonstrated that the use of serum cystatin $\mathrm{C}$, alone or with creatinine, improved expected target vancomycin trough achievement. Published pharmacokinetic analyses also suggest that cystatin C-based GFR estimates more accurately predict vancomycin clearance than creatinine clearance $[25,29,30,39]$. Furthermore, the current literature suggests that steady-state vancomycin troughs correlate more significantly with cystatin C-based models than creatinine-based models, largely due to reduced error among older individuals [26-28]. The present study demonstrates the potential utility of cystatin $\mathrm{C}$ to 

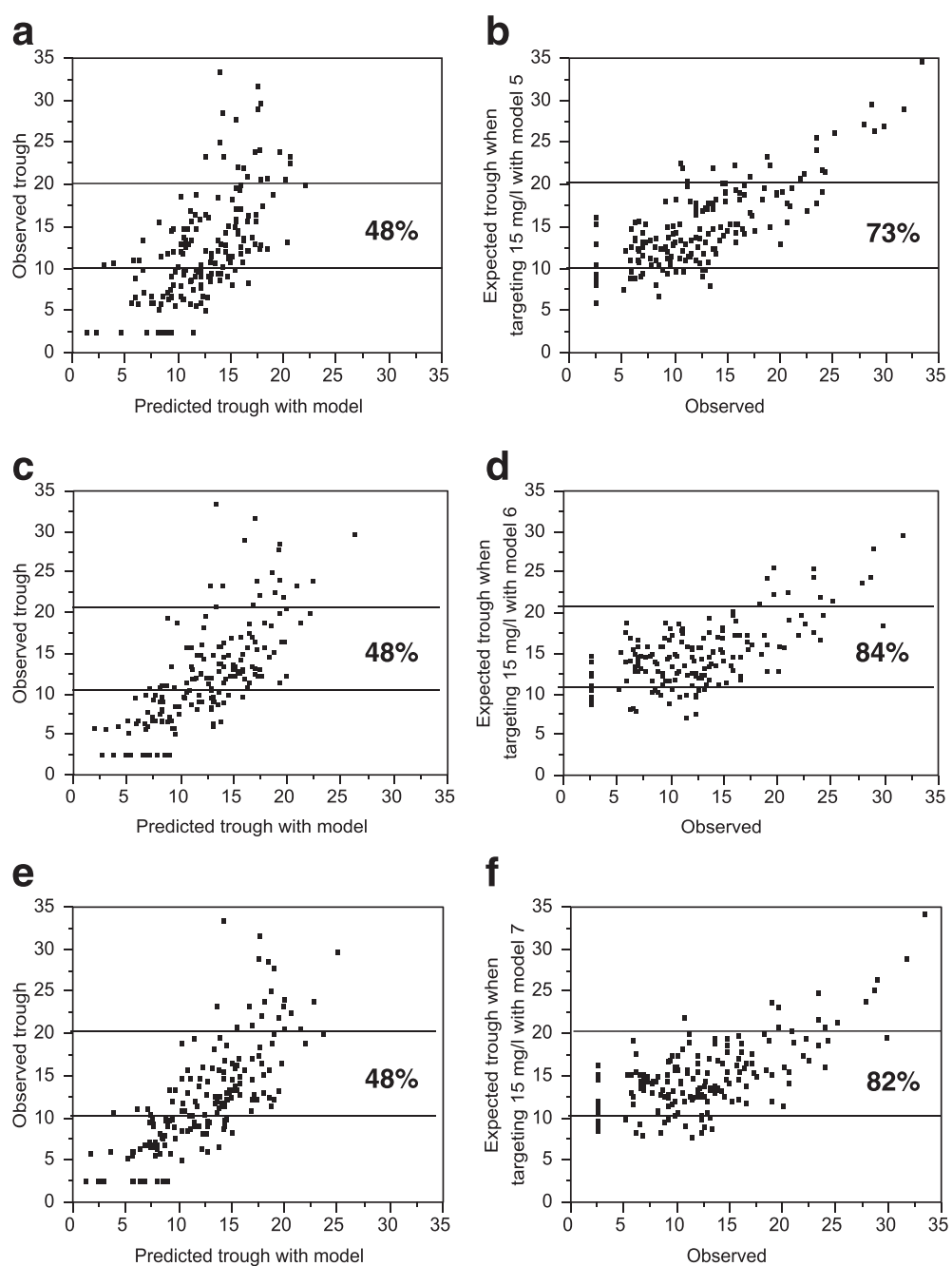

f

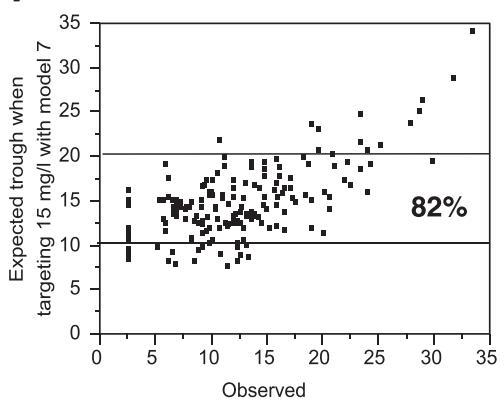

Figure 3 Graphical representation of the expected improvement in vancomycin trough target levels with application of the Chronic Kidney Disease Epidemiology Collaborative models. Predicted trough for each model ( $x$-axis) versus actual trough or versus the expected trough when targeting $15 \mathrm{mg} / \mathrm{L}$ with the model (y-axis) for model $5(\mathbf{a}, \mathbf{b})$, model $6(\mathbf{c}, \mathbf{d})$, and model $7(\mathbf{e}, \mathbf{f})$. The improvement in the proportion that would have an expected trough of 10 to $20 \mathrm{mg} / \mathrm{L}$ for each model is also shown. The more refined analysis targeting a trough of 10 to 15 or 15 to $20 \mathrm{mg} / \mathrm{L}$ (depending on the clinical indication for treatment) is presented in the text and tables.

achieve desired vancomycin trough levels in a real-world setting.

Although there is much emphasis on drug dose adjustment for patients with CKD (GFR $<60 \mathrm{~mL} / \mathrm{min}$ ), we found that the greatest improvement in target trough attainment was among patients without CKD (GFR $>60 \mathrm{~mL} / \mathrm{min}$ ). Indeed, the cystatin C-based models particularly improved predicted troughs among those with a GFR of more than $120 \mathrm{~mL} / \mathrm{min}$, a group in whom underdosing frequently occurs under usual clinical care [40]. These findings are similar to those of another recent report which demonstrated that cystatin $\mathrm{C}$ performed better than creatinine clearance for vancomycin dosing when the serum creatinine was not more than $1.2 \mathrm{mg} / \mathrm{dL}$ [39].
Our study expands upon previous work because it accounts for other clinically relevant non-GFR factors in the predictive model, including the use of a vancomycin loading dose and the total dose given prior to the trough level. As expected, loading doses were not associated with predicted vancomycin trough since troughs were measured under steady-state conditions. Although vancomycin loading has the theoretical pharmacokinetic benefit of expediting the time to a higher serum drug concentration and potential clinical effect (not measured in this study), our study detected no impact of loading on steadystate blood levels among the $37 \%$ of patients in whom one was used [41]. Drug dosing recommendations by the US Food and Drug Administration and those used in clinical practice are based largely on GFR estimates expressed in 


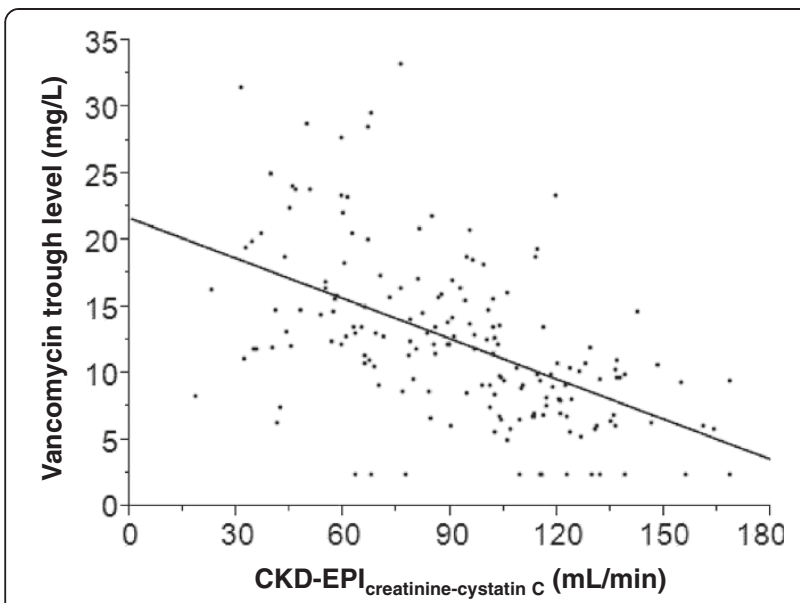

Figure 4 Association between vancomycin trough concentrations and estimated glomerular filtration rate (GFR)

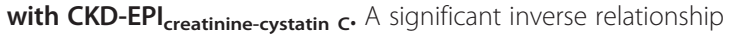
exists between GFR and vancomycin troughs $(P<0.0001)$. Patients with a GFR of more than $120 \mathrm{~mL} / \mathrm{min}$ rarely reached the minimum acceptable trough of 10 mg/L. CKD-EPI, Chronic Kidney Disease Epidemiology Collaborative.

milliliters per minute not corrected for BSA [26-28]. Therefore, also unlike most previous investigators, we converted eGFR to milliliters per minute using the Du Bois formula for BSA in order to remove the $1.73 \mathrm{~m}^{2}$ normalization factor [12,37]. The current models could be used to develop dosing algorithms that include eGFR, desired interval, and trough goal. If serum cystatin $C$ levels are not available at therapy initiation, we suggest that initial recommendations could use the eGFR creatinine model (model 5) with subsequent dose modification based on the $\mathrm{eGFR}_{\text {creatinine-cystatin C }}$ model (model 7) once available.

The exact reason why serum cystatin $C$ performed better than serum creatinine for vancomycin trough prediction is not entirely clear. Numerous studies among stable ambulatory patients have shown that cystatin Cbased equations perform similar to creatinine-based equations in estimating GFR when either marker is used in isolation [12,20,21]. However, cystatin C may more closely capture subtle fluctuations in GFR among acutely ill, hospitalized patients than serum creatinine [42]. Inflammation is an important non-GFR determinant of increased cystatin $C$ levels $[43,44]$. In the hospital setting, rises in cystatin $\mathrm{C}$ could reflect inflammation secondary to infection, and the severity of infection, hence an increase in cystatin C, may predict a GFR decline which ultimately impacts vancomycin trough levels. The $15 \mathrm{~mL} / \mathrm{min}$ lower GFR estimate by CKD-EPI cystatin C $_{\text {C }}$ than by CKD-EPI $I_{\text {creatinine }}$ is consistent with both hypotheses. In addition, the biggest improvement in troughs was among individuals with higher levels of GFR, a group in whom cystatin $C$ appears to perform better than creatinine alone as a biomarker of GFR [12]. We also found that
GFR estimation may not actually be a necessary step for a vancomycin dosing model. Models 2 and 3 use cystatin $C$ without estimating GFR and perform similar to models 6 and 7. Furthermore, models 2 and 3 do not rely on the documentation of height. Given the historical reliance on GFR estimating equations for drug dosing, models using eGFR may be easier to implement in clinical practice.

There are several potential limitations of this study. The small proportion of non-Caucasian individuals included does not allow study of the impact that race and ethnicity could have on model performance. However, cystatin C GFR estimates have not been found to be significantly impacted by race, and the performance of the CKD-EPI equations in Caucasian populations has been established [12]. In addition, few patients in the present study were experiencing significant changes in renal function based upon serum creatinine at the time of inclusion. However, patients clearly developing AKI would not be dosed on a consistent schedule but instead would be dosed individually based upon random vancomycin levels. Indeed, any dosing algorithm will need to be suspended if the patient develops AKI. Patients with a body mass index of more than $32 \mathrm{~kg} / \mathrm{m}^{2}$ were also excluded. Obesity alters the pharmacokinetics of vancomycin and affects cystatin $C$ levels independent of GFR, and thus the performance of cystatin C-based dosing models in this population needs further study $[34,43]$. We emphasize that prospective testing of these models is needed to determine whether the expected improvement can be translated into actual improvement in target trough achievement. Also, though not the subject of the present study, future research should also evaluate whether any change in actual vancomycin target attainment with cystatin C-based dosing algorithms translates into improvements in therapeutic efficacy and safety.

\section{Conclusions}

We found that a model based on eGFR from CKDEPI $_{\text {creatinine-cystatin }} \mathrm{C}$ optimally predicts vancomycin trough levels. Target trough achievement (10 to $15 \mathrm{mg} / \mathrm{L}$ or 15 to $20 \mathrm{mg} / \mathrm{L}$ ) is expected to be about 2.5 -fold better with this model than current clinical practice. These findings are promising and encourage further investigation to prospectively validate the proposed or similar cystatin C-based vancomycin dosing models.

\section{Key messages}

- Vancomycin dosing in hospitalized adults infrequently achieves recommended target trough levels, perhaps due to suboptimal assessment of glomerular filtration rate.

- A novel cystatin C-based dosing model which includes eGFR with the CKD-EPI creatinine-cystatin $C_{\text {e }}$ equation was 
developed and is projected to result in a 2.5 -fold improvement in target trough attainment over usual care.

- Cystatin C is a promising GFR surrogate and further study is needed to evaluate its potential for medication dosing.

\section{Additional file}

\section{Additional file 1: Chronic Kidney Disease Epidemiology Collaborative (CKD-EPI) estimated glomerular filtration rate (eGFR) predictive models for vancomycin trough with and without both body surface area normalization for $1.73 \mathrm{~m}^{2}$ and weight.}

\section{Abbreviations}

AKI: acute kidney injury; BSA: body surface area; CKD: chronic kidney disease; CKD-EPI: Chronic Kidney Disease Epidemiology Collaborative: eGFR: estimated glomerular filtration rate; GFR: glomerular filtration rate; IDMS: isotope dilution mass spectrometry; SD: standard deviation.

\section{Competing interests}

The authors declare that they have no competing interests.

\section{Authors' contributions}

EF had full access to all of the data in the study and takes responsibility for the integrity of the data and the accuracy of the analysis. She helped to design the study, to gather data on included subjects in conjunction with the representatives of Mayo Validation Support Services cited in the Acknowledgments, to perform the statistical analysis, and to draft the manuscript. AR had full access to all of the data in the study and takes responsibility for the integrity of the data and accuracy of the analysis. He helped to design the study, to perform the statistical analysis, and to draft the manuscript. $J$ had full access to all of the data in the study and takes responsibility for the integrity of the data and accuracy of the analysis. He helped to design the study, to perform the statistical analysis, and to draft the manuscript. AV helped to design the study and to review the statistical analysis. SH and NV helped to gather data on included subjects in conjunction with the representatives of Mayo Validation Support Services cited in the Acknowledgments. KK and NL helped to review the statistical analysis. All authors reviewed the data, participated in discussions related to interpretation and read and approved the final manuscript.

\section{Acknowledgments}

The authors would like to thank Mary Karaus, David Dvorak, and Laura Hanson of Mayo Validation Support Services for their assistance with the study. This study was partially funded by Gentian AS, which also supplied reagents used for the cystatin $C$ particle-enhanced turbidimetric assay, and by the Mayo Foundation. Research funding played no role in the study design, analysis, or interpretation of the data or in the decision to submit the report for publication.

\section{Author details \\ ${ }^{1}$ Hospital Pharmacy Services, Mayo Clinic, 200 First Street SW, Rochester, MN 55905, USA. ²Division of Nephrology and Hypertension, Mayo Clinic, 200 First Street SW, Rochester, MN 55905, USA. ㄹivision of Epidemiology, Mayo Clinic, 200 First Street SW, Rochester, MN 55905, USA. ${ }^{4}$ Division of Pulmonary and Critical Care Medicine, Mayo Clinic, 200 First Street SW, Rochester, MN 55905, USA. ${ }^{5}$ Division of Infectious Diseases, Mayo Clinic, 200 First Street SW, Rochester, MN 55905, USA. ${ }^{6}$ Department of Laboratory Medicine and Pathology, Mayo Clinic, 200 First Street SW, Rochester, MN 55905, USA.}

Received: 4 February 2014 Accepted: 6 May 2014

Published: 29 May 2014

\section{References}

1. Levine DP: Vancomycin: a history. Clin Infect Dis 2006, 42:S5-S12.

2. Kirst HA, Thompson DG, Nicas TI: Historical yearly usage of vancomycin. Antimicrob Agents Chemother 1998, 42:1303-1304.
3. Ena J, Dick RW, Jones RN, Wenzel RP: The epidemiology of intravenous vancomycin usage in a university hospital. A 10-year study. JAMA 1993, 269:598-602.

4. Liu C, Bayer A, Cosgrove SE, Daum RS, Fridkin SK, Gorwitz RJ, Kaplan SL, Karchmer AW, Levine DP, Murray BE, Rybak MJ, Talan DA, Chambers HF: Clinical practice guidelines by the infectious diseases society of america for the treatment of methicillin-resistant Staphylococcus aureus infections in adults and children: executive summary. Clin Infect Dis 2011, 52:285-292.

5. Rybak M, Lomaestro B, Rotschafer JC, Moellering R Jr, Craig W, Billeter M, Dalovisio JR, Levine DP: Therapeutic monitoring of vancomycin in adult patients: a consensus review of the American Society of Health-System Pharmacists, the Infectious Diseases Society of America, and the Society of Infectious Diseases Pharmacists. Am J Health Syst Pharm 2009, 66:82-98.

6. Wunderink RG, Niederman MS, Kollef MH, Shorr AF, Kunkel MJ, Baruch A, McGee WT, Reisman A, Chastre J: Linezolid in methicillin-resistant Staphylococcus aureus nosocomial pneumonia: a randomized, controlled study. Clin Infect Dis 2012, 54:621-629.

7. Rybak MJ: The pharmacokinetic and pharmacodynamic properties of vancomycin. Clin Infect Dis 2006, 42:S35-S39.

8. Kullar R, Leonard SN, Davis SL, Delgado G Jr, Pogue JM, Wahby KA, Falcione $B$, Rybak MJ: Validation of the effectiveness of a vancomycin nomogram in achieving target trough concentrations of $15-20 \mathrm{mg} / \mathrm{L}$ suggested by the vancomycin consensus guidelines. Pharmacotherapy 2011, 31:441-448.

9. Moellering RC Jr, Krogstad DJ, Greenblatt DJ: Vancomycin therapy in patients with impaired renal function: a nomogram for dosage. Ann Intern Med 1981, 94:343-346.

10. Wilson J, Estes L: Mayo Clinic Antimicrobial Therapy: Quick Guide. 2nd edition. New York, NY: Oxford University Press, Inc.; 2012.

11. Cockcroft DW, Gault MH: Prediction of creatinine clearance from serum creatinine. Nephron 1976, 16:31-41.

12. Inker LA, Schmid CH, Tighiouart H, Eckfeldt JH, Feldman HI, Greene T, Kusek JW, Manzi J, Van Lente F, Zhang YL, Coresh J, Levey AS: Estimating glomerular filtration rate from serum creatinine and cystatin C. [Erratum appears in $\mathrm{N}$ Engl J Med. 2012 Aug 16;367:681]. N Engl J Med 2012, 367:20-29.

13. Lameire N, Van Biesen W, Vanholder R: Acute renal problems in the critically ill cancer patient. Curr Opin Crit Care 2008, 14:635-646.

14. Doi K, Yuen PS, Eisner C, Hu X, Leelahavanichkul A, Schnermann J, Star RA: Reduced production of creatinine limits its use as marker of kidney injury in sepsis. J Am Soc Nephrol 2009, 20:1217-1221.

15. Bucaloiu ID, Perkins RM, DiFilippo W, Yahya T, Norfolk E: Acute kidney injury in the critically ill, morbidly obese patient: diagnostic and therapeutic challenges in a unique patient population. Crit Care Clin 2010, 26:607-624.

16. Salazar DE, Corcoran GB: Predicting creatinine clearance and renal drug clearance in obese patients from estimated fat-free body mass. Am J Med 1988, 84:1053-1060.

17. Sherman DS, Fish DN, Teitelbaum I: Assessing renal function in cirrhotic patients: problems and pitfalls. Am J Kidney Dis 2003, 41:269-278.

18. Rule AD, Bailey KR, Schwartz GL, Khosla S, Lieske JC, Melton LJ 3rd: For estimating creatinine clearance measuring muscle mass gives better results than those based on demographics. Kidney Int 2009, 75:1071-1078.

19. Cocchetto DM, Tschanz C, Bjornsson TD: Decreased rate of creatinine production in patients with hepatic disease: implications for estimation of creatinine clearance. Ther Drug Monit 1983, 5:161-168.

20. Eriksen BO, Mathisen UD, Melsom T, Ingebretsen OC, Jenssen TG, Njolstad I, Solbu MD, Toft I: The role of cystatin C in improving GFR estimation in the general population. Am J Kidney Dis 2012, 59:32-40.

21. Rule AD, Bergstralh EJ, Slezak JM, Bergert J, Larson TS: Glomerular filtration rate estimated by cystatin $C$ among different clinical presentations. Kidney Int 2006, 69:399-405.

22. Schaeffner ES, Ebert N, Delanaye P, Frei U, Gaedeke J, Jakob O, Kuhlmann MK, Schuchardt M, Tolle M, Ziebig R, van der Giet M, Martus P: Two novel equations to estimate kidney function in persons aged 70 years or older. Ann Intern Med 2012, 157:471-481.

23. Anderson AH, Yang W, Hsu CY, Joffe MM, Leonard MB, Xie D, Chen J, Greene T, Jaar BG, Kao P, Kusek JW, Landis JR, Lash JP, Townsend RR, Weir MR, Feldman HI: Estimating GFR among participants in the Chronic Renal Insufficiency Cohort (CRIC) Study. Am J Kidney Dis 2012, 60:250-261.

24. Delanaye P, Cavalier E, Morel J, Mehdi M, Maillard N, Claisse G, Lambermont B, Dubois BE, Damas P, Krzesinski JM, Lautrette A, Mariat C: Detection of decreased glomerular filtration rate in intensive care units: serum cystatin C versus serum creatinine. BMC Nephrol 2014, 15:9. 
25. Hermida J, Tutor JC: Serum cystatin C for the prediction of glomerular filtration rate with regard to the dose adjustment of amikacin, gentamicin, tobramycin, and vancomycin. Ther Drug Monit 2006, 28:326-331.

26. Tanaka A, Aiba T, Otsuka T, Suemaru K, Nishimiya T, Inoue T, Murase M, Kurosaki Y, Araki H: Population pharmacokinetic analysis of vancomycin using serum cystatin $\mathrm{C}$ as a marker of renal function. Antimicrob Agents Chemother 2010, 54:778-782.

27. Tanaka A, Suemaru K, Otsuka T, Ido K, Nishimiya T, Sakai I, Hasegawa H, Inoue T, Murase $\mathrm{M}$, Yasukawa $\mathrm{M}$, Araki H: Estimation of the initial dose setting of vancomycin therapy with use of cystatin $\mathrm{C}$ as a new marker of renal function. Ther Drug Monit 2007, 29:261-264.

28. Tanaka A, Suemaru K, Otsuka T, Ido K, Nishimiya T, Sakai I, Hasegawa H, Yasukawa M, Inoue T, Murase M, Araki H: Hoek's formula, a cystatin C-based prediction formula for determining the glomerular filtration rate, is the most effective method for original adjusting the dosage of vancomycin. Int I Clin Pharmacol Ther 2007, 45:592-597.

29. Okamoto G, Sakamoto T, Kimura M, Ukishima Y, Sonoda A, Mori N, Kato Y, Maeda T, Kagawa Y: Serum cystatin $C$ as a better marker of vancomycin clearance than serum creatinine in elderly patients. Clin Biochem 2007, 40:485-490

30. Kees MG, Hilpert JW, Gnewuch C, Kees F, Voegeler S: Clearance of vancomycin during continuous infusion in intensive care unit patients: correlation with measured and estimated creatinine clearance and serum cystatin C. Int J Antimicrob Agents 2010, 36:545-548.

31. Schuck O, Teplan V, Sibova J, Stollova M: Predicting the glomerular filtration rate from serum creatinine, serum cystatin $C$ and the Cockcroft and Gault formula with regard to drug dosage adjustment. Int I Clin Pharmacol Ther 2004, 42:93-97.

32. Melton $\sqcup$ 3rd: The threat to medical-records research. N Engl J Med 1997, 337:1466-1470.

33. Kellum JA, Lameire N: KDIGO clinical practice guideline for acute kidney injury. Kidney Int Suppl 2012, 2:1-138.

34. Grace E: Altered vancomycin pharmacokinetics in obese and morbidly obese patients: what we have learned over the past 30 years. $J$ Antimicrob Chemother 2012, 67:1305-1310.

35. Vancomycin Full Prescribing Information. Lake Forest, IL: Hospira, Inc; 2011:1-8.

36. Blirup-Jensen S, Grubb A, Lindstrom V, Schmidt C, Althaus H: Standardization of Cystatin C: development of primary and secondary reference preparations. Scand J Clin Lab Invest Supp/ 2008, 241:67-70.

37. Du Bois D, Du Bois E: Clinical calorimetry: Tenth paper. A formula to estimate the approximate surface area if height and weight be known. Arch Intern Med 1916, 17:863-871.

38. Kidney Disease: Improving Global Outcomes (KDIGO) CKD Work Group: KDIGO Clinical practice guideline for the evaluation and management of chronic kidney disease. Kidney Int Supp/ 2013, 3:1-150

39. Chung JY, Jin SJ, Yoon JH, Song YG: Serum cystatin C is a major predictor of vancomycin clearance in a population pharmacokinetic analysis of patients with normal serum creatinine concentrations. J Korean Med Sci 2013, 28:48-54.

40. Minkute R, Briedis V, Steponaviciute R, Vitkauskiene A, Maciulaitis R: Augmented renal clearance - an evolving risk factor to consider during the treatment with vancomycin. J Clin Pharm Ther 2013, 38:462-467.

41. Truong J, Levkovich BJ, Padiglione AA: Simple approach to improving vancomycin dosing in intensive care: a standardised loading dose results in earlier therapeutic levels. Intern Med J 2012, 42:23-29.

42. Inker LA, Okparavero A: Cystatin C as a marker of glomerular filtration rate: prospects and limitations. Curr Opin Nephrol Hypertens 2011, 20:631-639.

43. Rule AD, Bailey KR, Lieske JC, Peyser PA, Turner ST: Estimating the glomerular filtration rate from serum creatinine is better than from cystatin C for evaluating risk factors associated with chronic kidney disease. Kidney Int 2013, 83:1169-1176.

44. Stevens LA, Schmid CH, Greene T, Li L, Beck GJ, Joffe MM, Froissart M, Kusek $J W$, Zhang YL, Coresh J, Levey AS: Factors other than glomerular filtration rate affect serum cystatin C levels. Kidney Int 2009, 75:652-660.

\section{doi:10.1186/cc13899}

Cite this article as: Frazee et al:: Serum cystatin C predicts vancomycin trough levels better than serum creatinine in hospitalized patients: a cohort study. Critical Care 2014 18:R110.

\section{Submit your next manuscript to BioMed Central and take full advantage of:}

- Convenient online submission

- Thorough peer review

- No space constraints or color figure charges

- Immediate publication on acceptance

- Inclusion in PubMed, CAS, Scopus and Google Scholar

- Research which is freely available for redistribution 